\title{
UNA NOVEDAD EN BYTTNERIA (STERCULIACEAE)
}

\author{
CARMen L. CRistóBAL \\ Instituto de Botánica del Nordeste, casilla de correo 209. 3400 Corrientes, República Argentina \\ ibone@agr.unne.edu.ar
}

\begin{abstract}
Byttneria osaënsis Cristóbal from the Osa Península, located on the south Pacific of Costa Rica, is described and illustrated. Because of its habit and floral morphology, the new species belongs to the section Vahihara J. Ar. Considering that many duplicates were identified as B. pescapriifolia Britt. (=B. pescapraeifolia), a related species, comparative data on both species are provided.

Resumen. Se describe e ilustra Byttneria osaënsis Cristóbal, de la Península de Osa, en el Pacífico sur de Costa Rica. Debido a su hábito y morfología floral, la nueva especie pertenece a la sección Vahihara J. Ar. En vista de que los especímenes fueron previamente determinados como B. pescapriifolia Britt. (=B. pescapraeifolia), una especie relacionada, se agregan datos comparativos.
\end{abstract}

Palabras ClaVe / Key words: Sterculiaceae, Byttneria sectio Vahihara, Byttneria osaënsis, B. pescaprifolia, Costa Rica

La nueva especie descrita aquí pertenece a la sección Vahihara J. Ar. (Arènes 1956). Ésta se caracteriza porque sus miembros son bejucos inermes con pétalos de morfología compleja, que poseen una fosa en la cara interna de la capucha. Es una sección pantropical y ocupa toda el área del género. En Madagascar se produjo una especiación verdaderamente explosiva; allí se reconocen 27 especies, todas endémicas (Cristóbal 1976). En América viven sólo 13 especies, por lo que considero el nuevo hallazgo especialmente interesante. En América Central, Byttneria sección Vahihara tiene ahora tres especies, dos de las cuales habitan en Costa Rica.

\section{Byttneria osaënsis Cristóbal, sp. nova}

TIPO: Costa Rica. Puntarenas; cantón de Osa, Península de Osa, Reserva Forestal Golfo Dulce, entrada a Chocuaco, Bahía Chal, 843'20"N, 83²6'30"W, 15 nov 1992 (fr), Reinaldo Aguilar 1468 (Holotipo: CR, Isotipos: CTES, MO). FIG. 1.

Planta scandens inermis, foliis integribus, subcoriaceis, rigidis, elipticis, lamina ad basim rotundata vel subcordata; nervi medii basis cum nectario nigrescenti, prominenti, instructo, 5-6 $\mathrm{mm}$ longo; hypophyllo heterotricho, pilis stellatis, diminutis, in areolis hialinis, sed supra venis rufis; petala glabra, cum lamina lanceolata; fructus complanatus, lignosus, coccis ca. 4 cm longis et 3,6 cm latis, castaneo-rubescentibus, aculeis piramidalibus, 2-4 mm longis, sparsis, acutis, striatis, pubescentibus, pilis diminutis, simplicibus.

Liana con hojas simples, enteras, elípticas, lámina con base redondeada o subcordada, ápice subagudo, 9,5-15 cm de largo x 7-12 cm de ancho, subcoriáceas, claramente heterótricas, venación mayor y menor sobresaliente en el hipofilo, pelos estrellados muy pequeños y con numerosos radios, en las aréolas pelos hialinos cubriendo la superficie y pelos rojos dispersos, también sobre las venas, dando al hipofilo una tonalidad rojiza; nectario ubicado en la base de la vena media, 5-6 mm de largo, calloso, negro, abultado, con límites bien definidos, domacios amarillentos en las axilas de las venas secundarias y terciarias, constituidos por pelos rectos, ordenados en filas enfrentadas, a modo de un cepillo, una fila sobre la cara interna de la vena media y otra sobre la vena secundaria. Epifilo subglabro, con pelos estrellados muy pequeños, dispersos sobre las venas. Pecíolo terete, $8-10 \mathrm{~cm}$ de largo y $c a .3 \mathrm{~mm}$ de diám. Flores rojas, reunidas en inflorescencias axilares amplias de hasta $5 \mathrm{~cm}$ de largo. Pétalos glabros, uña acintada, membranácea, lámina carnosa, de sección redondeada, afinada hacia ambos extremos, porción superior de la uña con alas agudas, recurvadas, en la cara interna de la capucha de la uña engrosamientos delimitando una fosa profunda; pétalo adosado en 


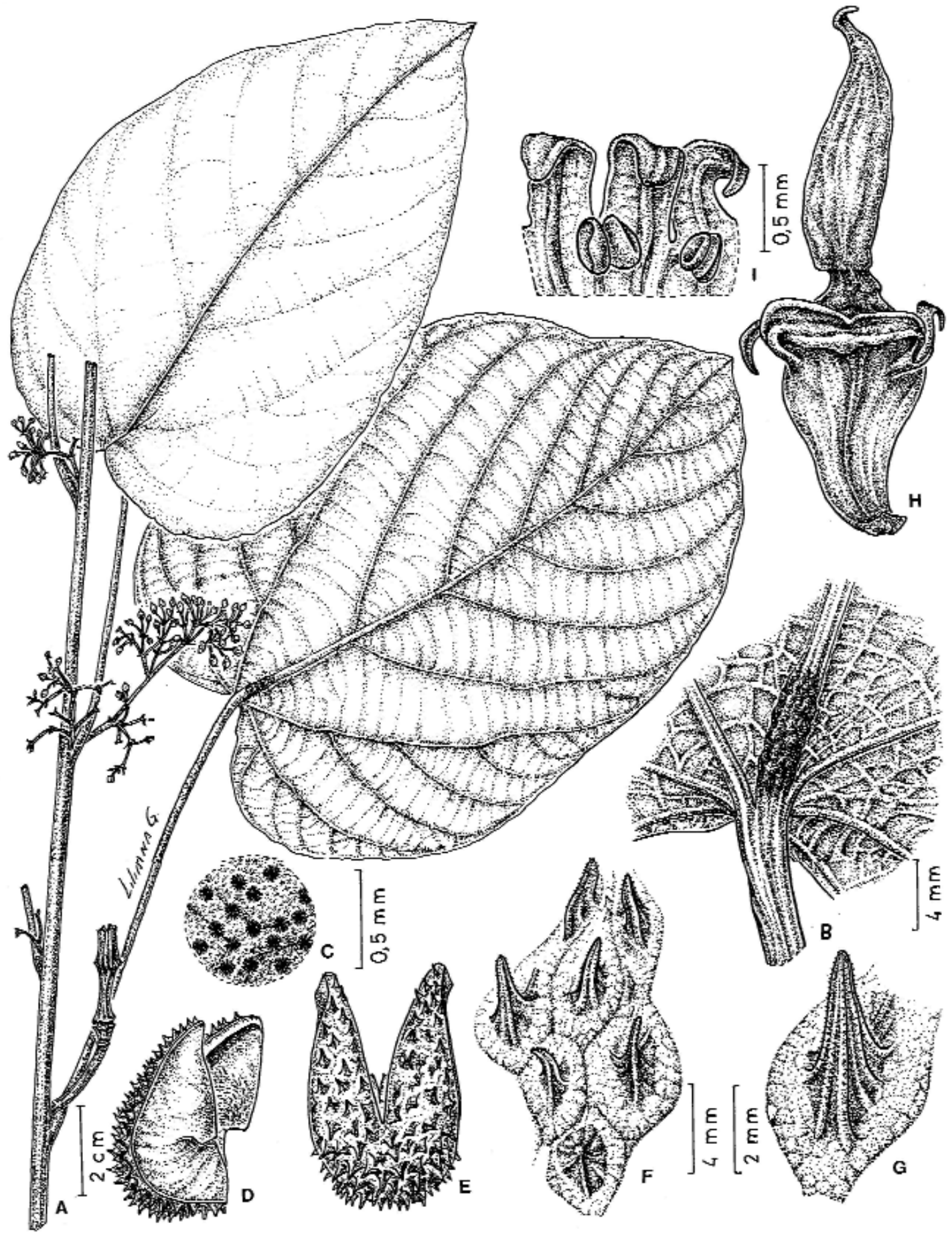

Fig. 1. Byttneria osaënsis Cristóbal. A - Rama florífera. B - Porción de la base foliar con el nectario. C - Detalle del indumento del hipofilo. D - Coco dehiscente, vista 3/4 perfil interno. E - Coco, cara externa. F - Detalle de los aculéolos. G - Aculéolo, mostrando estrías y pubescencia. H - Pétalo, cara interna. I - Porción del tubo estaminal, cara externa, mostrando tres estaminodios y dos estambres. Dibujo de Liliana Gómez. A-C, H-I: Aguilar 2017 (paratipo, CTES). D-G: 

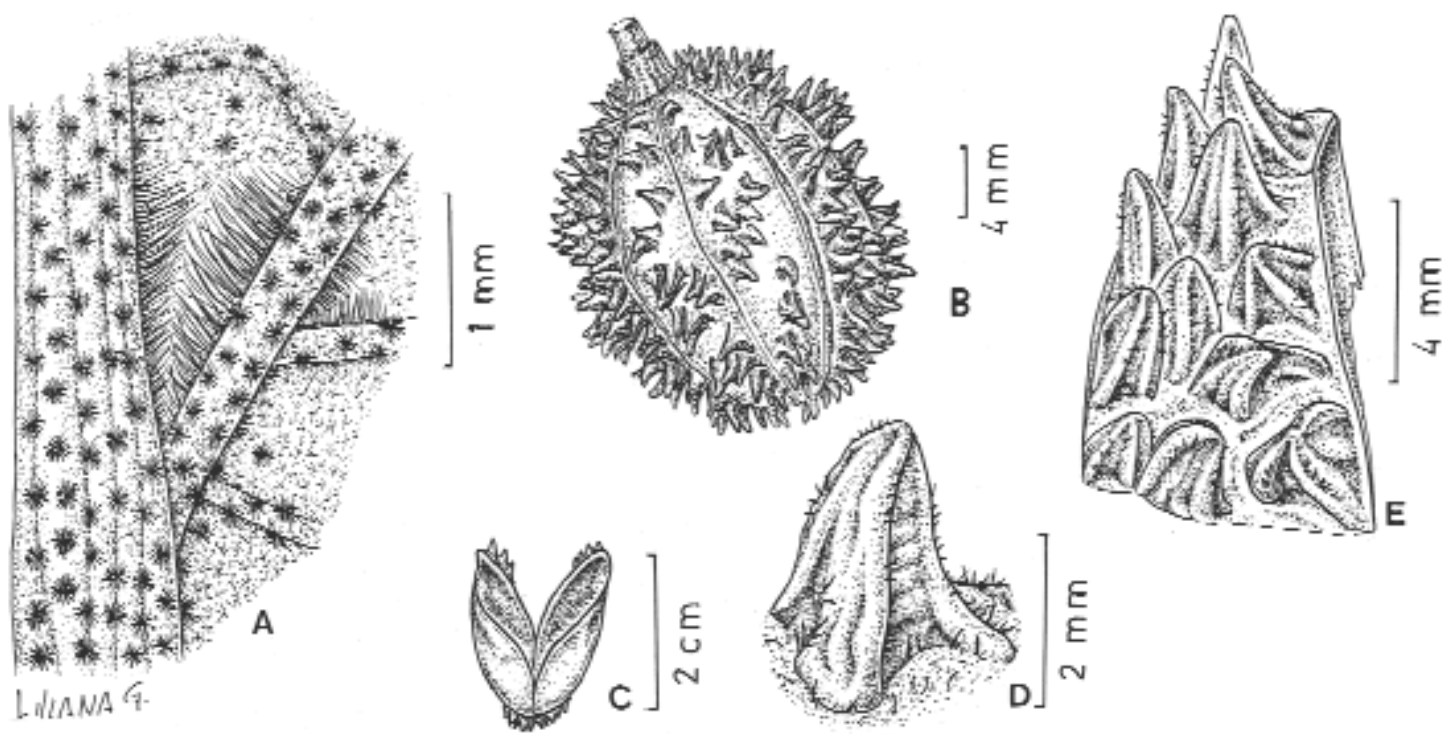

Fig. 2. Byttneria pescapriifolia Britton. A - Domacio piloso. B - Fruto completo. C - Coco dehiscente. D - Aculéolo del fruto. E - Detalle de la superficie del fruto. Todo de A.R.S. Oliveira \& al. 590, Acre, Brasil (CTES).

este punto al correspondiente estaminodio. Tubo estaminal campanulado, estaminodios soldados hasta las anteras. Fruto leñoso, esferoidal, algo complanado, castaño-rojizo, de $c a .40 \mathrm{~mm}$ de largo x $46 \mathrm{~mm}$ de diám., disgregándose en 5 cocos dehiscentes; cara interna cubierta de pelos erectos, finos, hialinos, cara externa con aculéolos de $c a$. 2-4 mm de largo x $3 \mathrm{~mm}$ de ancho en la base, piramidales, agudos, estriados, leñosos, con pelos diminutos, simples, gruesos, brillantes.

Paratipo. Costa Rica: Puntarenas; cantón de Osa, Península de Osa, Reserva Forestal Golfo Dulce, Bahía

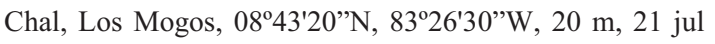
1993 (fl). Bejuco. Flores con pedúnculo rojo opaco; perianto blanco-rojizo, estambres rojo oscuro. Reinaldo Aguilar 2017 (CR, CTES, MO).

Las especies americanas relacionadas se pueden diferenciar por medio de la siguiente clave:

1 Hojas membranáceas 2

2. Hojas aserradas (Oaxaca, México) B. capillata Cristóbal

2. Hojas enteras. Cocos con aculéolos aciculares de 6$17 \mathrm{~mm}$ de largo; lámina de los pétalos blanca, ancha, plana (México a Bolivia, Tahití)

B. catalpifolia Jacq. ssp. catalpifolia

1. Hojas subcoriáceas, enteras 3

3. Nectario foliar calloso, negro, abultado, 5-6 mm de largo; frutos esféricos, algo complanados, $40 \mathrm{~mm}$ de largo x 46 mm de ancho, castaño-rojizos; aculéolos piramidales, regularmente distribuidos, estriados, de 2$4 \mathrm{~mm}$ de largo (Costa Rica) ...... B. osaënsis Cristóbal

3. Nectario foliar ca. $2-3 \mathrm{~cm}$ de largo, liso, negro, con límites indefinidos; frutos elipsoidales, 20-25 mm de largo x $16 \mathrm{~mm}$ de ancho; aculéolos irregularmente piramidales, 2-5 $\mathrm{mm}$ de largo (Cuenca Amazónica.) B. pescapriifolia Britton

En B. osaënsis los cocos son de ca. $40 \mathrm{~mm}$ de largo x $46 \mathrm{~mm}$ de ancho, por lo que el fruto es esférico, algo complanado, con los aculéolos regularmente distribuidos, piramidales, agudos, estriados y dispuestos en el centro de un área poligonal. En B. pescapriifolia el fruto es elipsoide, de $c a$. $20-25 \mathrm{~mm}$ de largo x $16 \mathrm{~mm}$ de ancho. Los aculéolos son más gruesos e irregulares y están apiñados, pero dejan libre la línea de dehiscencia y la de unión de cada coco; poseen pelos simples, diminutos, brillantes; en la base de los aculéolos y sobre la superficie del fruto se hallan pelos más largos, dispersos. Los aculéolos caen junto con el exocarpo, de manera que la superficie del fruto queda pelada y lisa (fig. 2). Ambas especies tienen domacios de tipo piloso, ubicados en las axilas de las venas basales y de las venas secundarias con la vena media. En $B$. pescapriifolia los domacios son amarillentos y más grandes, tanto que se ven a simple vista; en la nueva especie son rojizos, por la coloración del indumento. 


\section{LITERATURA CITADA}

Arènes, J. 1956. Contribution a l'etude des Sterculiacées de Madagascar, XV Revision des Byttneria Malgaches. Mém. Inst. Sci. Madagascar. Sér. B. Biol.Vég.7: 84-111.

Cristóbal, C.L. 1976. Estudio taxonómico del género Byttneria (Sterculiaceae). Bonplandia 4: 1-428, 100 figs. 